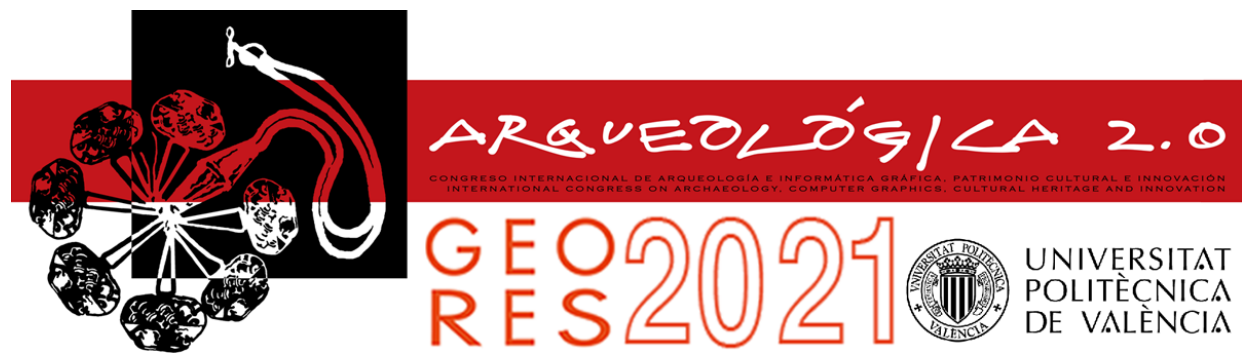

Proceedings of the joint international event $9^{\text {th }}$ ARQUEOLÓGICA

$2.0 \& 3^{\text {rd }}$ GEORES

Valencia (Spain).

26-28 April 2021

\title{
INTEGRATING LASER SCANNING AND GEO-MECHANICAL SURVEY IN CONSERVATIVE RESTORATION; THE CASE OF FIRST WORLD WAR'S CIMA GRAPPA MILITARY SHRINE, ITALY
}

\author{
Francesco Mugnaia, ${ }^{a}$, Paolo Farina ${ }^{b}$, Grazia Tucci ${ }^{a}$ \\ ${ }^{a}$ Department of Civil and Environmental Engineering, University of Florence, Via di S.Marta 3,50139 Firenze, Italy. \\ francesco.mugnai@unifi.it; grazia.tucci@unifi.it \\ b Geoapp s.r.I.,Viale Spartaco Lavagnini 70-72, 50129 Firenze, Italy. paolo.farina@geoapp.it
}

\begin{abstract}
:
The work presents results obtained performing a survey campaign specifically designed to formulate an effective restoration project in a critical context. Within the remarkable project, promoted and financed by the Italian Presidency of the Council of the Ministers, and the Italian Ministry of Defence, for designing the conservative restoration plan of the Military Shrine in Cima Grappa (Italy), the assessment of the overall tunnels' stability and a report of the state of conservation of the underground area has been produced. Exploiting the most advanced laser scanning survey technique, and some specific algorithms for point cloud analysis, several outputs have been generated, in particular a detailed geometrical 3D reconstructions of man-made and natural tunnels coating materials, geo-mechanical survey of rock mass, map of rock collapses and cinematic analysis of instability processes. The integration of the laser scanning technique with the most commonly used Scan-line survey for rock-mass characterization and architectural surveys, allowed to perform advanced analysis even in a high-risk study area as the one considered in the restoration project, which is represented by a predominant subterranean development. Most of the tunnels and underground spaces, displayed rock collapses and diffuse active instability processes that certainly could have drastically slowed down surveys and analysis. The adopted techniques allowed to rapidly proceed in acquiring data end to deliver sound outputs. This paper aims to report both a general description of the project, spending some words on the historical value of the place and describing the complex environment of work, and a detailed depiction of the performed survey activities with particular attention in showing laser scanning survey and the obtained results.
\end{abstract}

Keywords: laser scanning, conservative restoration, kinematic analysis, 3D digital model, segmentation

\section{Introduction}

Some authors reveal that the politization of the fallen could be the true objective of the monumental ossuaries that Fascist Leadership built after the first world war (Malone, 2017).

In addition to its historical value and the noticeable cultural and architectural heritage, sometimes old witnesses, even when the told story concerns war, suffering, death and poverty, need to be remembered, if only to prevent certain events from happening again.

However, it undisputed how the project of conservative restoration of the Cima Grappa Military Shrine and of the revival of the annexed buildings, of the former NATO base and of the related neighbouring areas, assumes extraordinary importance not only for the complexity and heterogeneity of the envisaged interventions, but also for the historical and programmatic legislative framework of which the Cima Grappa complex is a central and strategic part.

Promoted and financed by the Italian Presidency of the Council of the Ministers, and the Italian Ministry of Defence, the restoration project insists on a mountain area on the top of Monte Grappa (also called "Cima del Grappa"), in particular the municipal area of Crespano del Grappa, Borso del Grappa and Paderno del Grappa in the Province of Treviso, Cismon del Grappa in the Province of Vicenza and Seren del Grappa in the Province of Belluno, in the geographic area of the Venetian Prealps. The intervention area can be conveniently divided into two sectors:

- The south area, consisting of the Shrine and the surrounding monumental complex, which in turn includes other celebratory elements (the Via Eroica and the Porta Roma, the Observatory, the Sacello della Madonnina) and defence and fortification works carried out during the First

“Corresponding Author: Francesco Mugnai, francesco.mugnai@unifi.it 
World War (the Vittorio Emanuele III Gallery and the Milan Barracks);

- The north area (Fig. 1), which host the site of the former NATO base and the relevant military perimeter

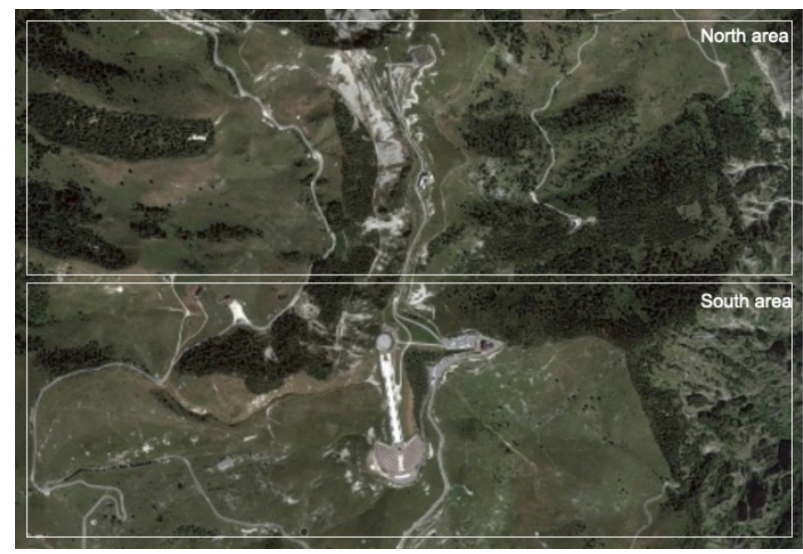

Figure 1: Aerial Orthophoto of the studied area.

The restoration project has driven by a quite extensive program that involved the various sections of the monumental complex.

Figure 2 shows the locations of the various rooms and sections in which the interventions have planned. In particular 1) Preventive environmental restoration works; 2) Scientific conservative restoration of the Shrine including Italian Ossuary, Via Eroica, Rome Portal and Austro-Hungarian ossuary as well as the observatory located in the EX NATO area; 3) Restructuring and transformation into an equipped museum of the Milan Barracks, connection restoration pedestrian staircase from the Austro-Hungarian cemetery to Piazza Cadorna; 4) Underground connection between the Milan Barracks and the former underground infirmary, with related securing of the infirmary itself; 5) Restoration of the Vittorio Emanuele III tunnel up to the connection with the underground ossuary; 6) Demolition of closing diaphragms of the underground ossuary and scientific restoration of the same; 7) Reconstruction of rainwater storage tank; 8) Demolition of former NATO barracks, garage building and pump room, and construction of green furniture areas; 9) Connection of the new storage tank to the autoclave and distribution of the water supply pipes along the Vicentina shoulder (south-east side) of the Cima del Grappa, in order to connect the Bassano Refuge to today in operation and prepare the water supply for possible other building interventions in the area.

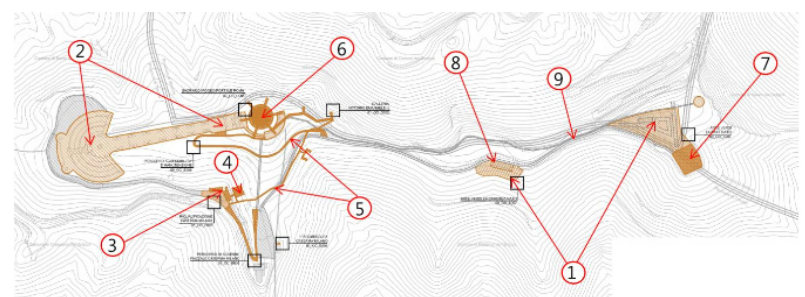

Figure 2: Map of restoration interventions.

The paper focuses in particular on the intervention number 4 , especially on securing the former infirmary room and tunnels to access this and the other main gallery named Galleria Vittorio Emanuele. Other than serving as linking path to access the other areas of the site, the ex-infirmary is one of the main highlights, an "archaeological" path of war in the mountain heart.

The area of interest, mainly represented by underground tulles (Fig. 3 ) is strongly affected by a generally poor state of conservation, as a matter of facts, several rock collapses have occurred in the underground infirmary environment and the access tunnels during the last few years (Fig. 4).
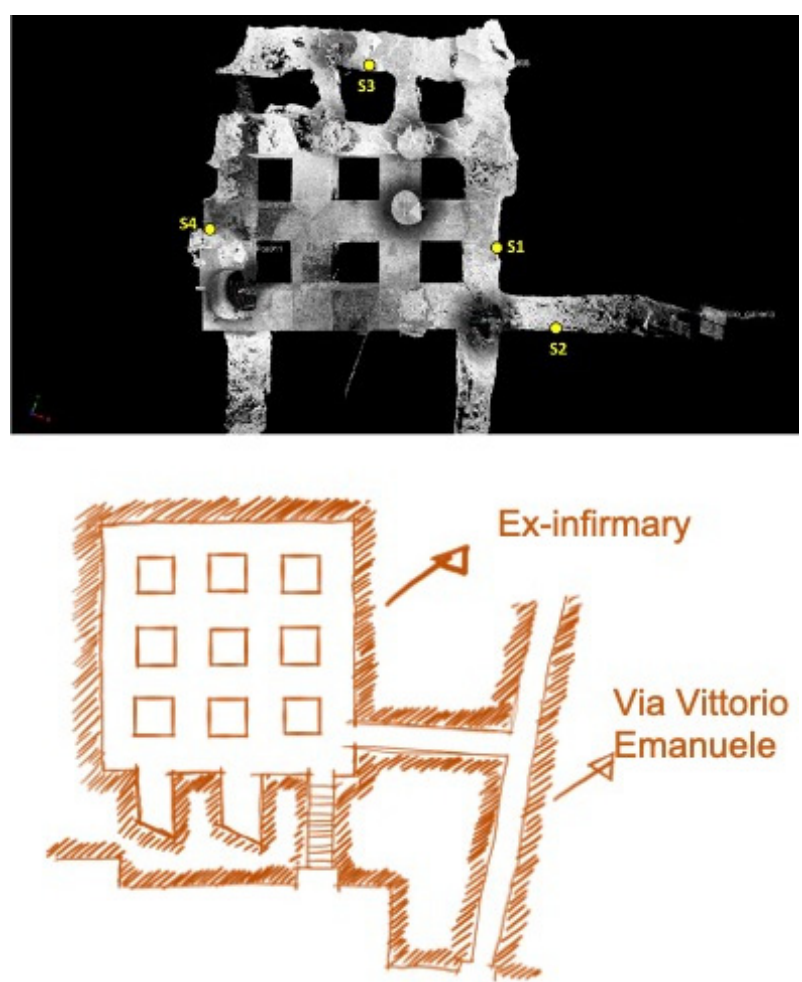

Figure 3: Top view of the Infirmary from 3D Point Cloud. S from 1 to 4 are scanning positions. The sketch on the right shows the position of Via Vittorio Emanuele.

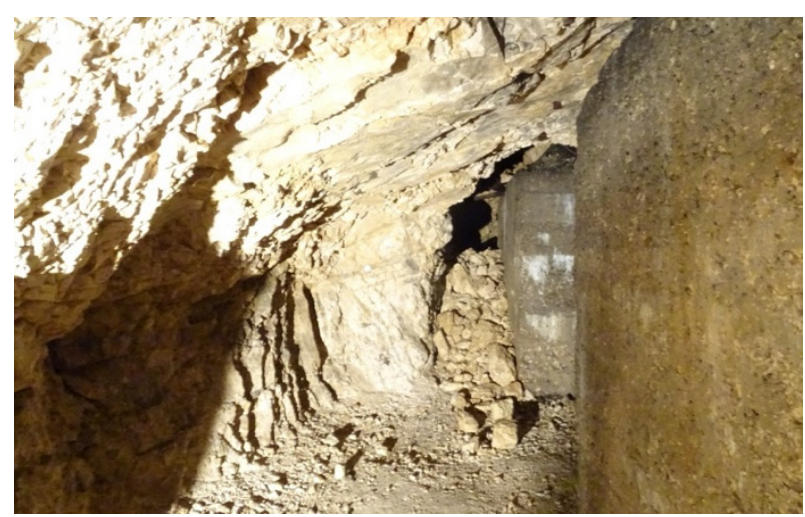

Figure 4: View of vault collapse within the infirmary tunnel.

This paper follows a well-established path (Bonora, Chieli, Spanò, Testa, \& Tucci, 2003; Bitelli et al., 2017; Castagnetti, Bertacchini, Capra, \& Dubbini, 2012; Grussenmeyer et al., 2012; Chías, Abad, Echeverría, De Miguel, \& Llorente, 2017; Lo Brutto, Sciortino, \& Garraffa, 2017), of using remote sensing and 3D surveys techniques (Thiel, \& Wehr, 2004; Wagner, Ullrich, Ducic, Melzer, \& Studnicka, 2006; Varady, Facello, \& Terek, 
2007; Remondino et al., 2011; Remondino, 2011; Tucci, Bonora, Fiorini, \& Conti, 2016; Chías, Abad, Echeverría De Miguel, \& Llorente, 2017) to support out of the ordinary conservative restoration projects in a complex work environment (Gallay et al., 2015, Gigli, Mugnai, Leoni, \& Casagli, 2009, Roncella, Forlani, \& Remondino, 2005, Gracchi, Lotti, \& Saccorotti, 2017).

A detailed geo-mechanical characterization of the former infirmary underground area has been therefore necessary in order to properly plan specific consolidating interventions. For this purpose, a) a high-resolution laser scan survey has been performed (Mucchi et al., 2018; Mugnai, Ridolfi, Bianchi, Franchi, \& Tucci, 2019) and b) 3D meshes of the area have been extracted. By automatically extracting rock-mass characteristics (surface orientation, number of cracks, spacing, frequency of cracks) the traditional geo-mechanical survey has been improved and extended to the whole exinfirmary area, including spaces and surfaces not completely accessible by technicians, and with an associated high-risk of rock collapse.

With such a dataset, the traditional geo-mechanical survey can be improved with information automatically extracted from the point clouds produced by the laser scanner.

\section{Methods}

In order to obtain the mechanical properties of the rock mass a geo-mechanical survey (Priest, 1993; Priest, \& Hudson, 1976) of the calcareous rock mass surfacing in the infirmary rooms, dug under the Cima Grappa, near the Milan barracks, was carried out. It consisted in some steps, in particular:

1) Geo-mechanical characterization of intact rock;

2) Geo-mechanical characterization of discontinuities;

3) Geo-mechanical characterization of the Rock Mass.

A laser scanning survey has been used to extract geometries. The Laser Scanner model is a Riegl LMSZ420i ground-based in Table 1.

Table 1: Laser Scanner hardware parameters.

\begin{tabular}{c|c} 
Parameter & Value \\
\hline Measurement Range & $0.2-1000 \mathrm{~m}$ \\
Accuracy & $10 \mathrm{~mm}$ \\
Laser class 1 & 1 \\
Minimum angle step-width & $0.004^{\circ}$
\end{tabular}

\subsection{Integration of classic geo-mechanical scan line survey}

In correspondence of not accessible areas, or in correspondence of areas prone to collapsing events, the classic geo-mechanical survey (scan-line detection method. citation) of the rock mass has been substituted with measures obtained from Laser Scanning datasets. In particular, the results of the geo-mechanical analysis thus obtained were combined with the results of the analysis of the point clouds acquired by the laser scanner. For the geo-mechanical characterization of the intact rock, tests were also carried out in the laboratory on samples of irregular shape taken on-site, however, as the paper focuses on Laser Scanning and analysis related to the acquired dataset.

\subsection{Acquisition Campaign}

A Riegl LMS-Z420i laser scanner model has been employed to perform the acquisition campaign (Fig. 5). The thirteens Scan Positions allowed to cover the entire areas of the ex-infirmary, adjacent to the Milan Barracks.

In order to obtain a comprehensive acquisition of both the tunnel vertical flanks and of the vaults, the laser scanner instrument has been deployed both in a vertical and horizontal configuration. The horizontal configuration has been mostly adopted in correspondence with the main collapses. For each shooting position, low-resolution framing scans and detail scans were acquired. A total of over 40 million points were thus acquired, one point $/ \mathrm{cm}^{2}$ is the average point cloud density of the processed point clouds after optimisation and unification. Before proceeding with laser scanning acquisition, some targets/reflectors were positioned within the scene.

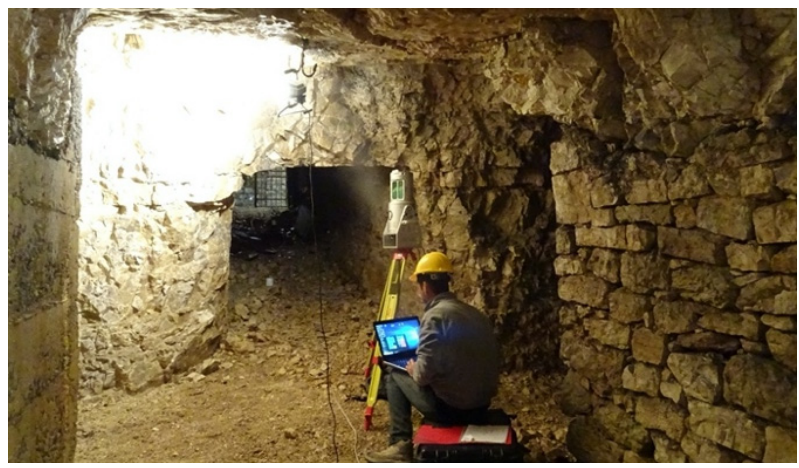

Figure 5: Tunnel area, Scan position $n^{\circ} 3$.

The use of reflectors is linked to the possibility for the acquisition software to recognize the same in the various scans in order to then combine them into a single cloud of points, minimizing the problems related to the presence of shaded areas.

\section{Data Analysis}

The accuracy in the alignment procedure of the scans has been improved by applying the Multi-Station Adjustment algorithm, (MSA) developed by Riegl (RIEGL, 2004), based on the recognition of homologous plans materialized for each scan (which therefore require portions of scanned surfaces in common between them) and their iterative alignment, up to minimizing the position differences (Fig. 6).

Due to the impossibility of acquiring the coordinates of the reflectors placed outside with acceptable accuracy via GPS (for lack of GPRS / UMTS coverage), the point clouds were oriented using as reference the walls of the Milan barracks, whose orientation was measured by compass and verified by georeferenced aerial photos.

Four traditional geo-mechanical surveys were carried out with the scanline method (scanline survey) at the main outcrop portions of the limestone rock mass inside the hospital wing, plus a series of random measures to complete the sample. in areas where the extension of the outcrops is more limited. The traditional geo-mechanical 
survey (Hoek, 1999) is however highly limited if the area to be investigated is inaccessible or unreachable, or, as in the case in question, very articulated and intensely fractured.

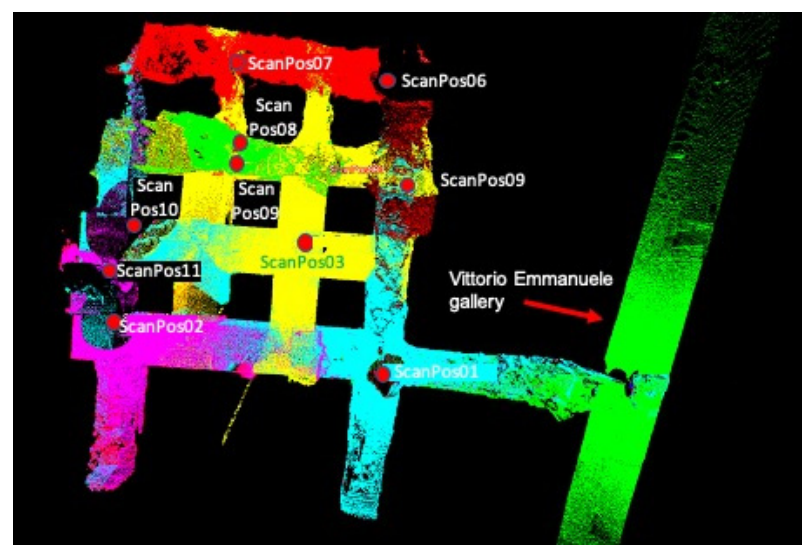

Figure 6: Top view of the Infirmary from the total point cloud. Each point clouds is showed with a different colour. Red dots represent Scan Positions.

Fortunately, by exploiting advanced techniques, it is possible to obtain effective data, even if the adopted technique has not been specifically designed for the selected application (Olsen, Kuester, Chang, \& Hutchinson, 2013; Mugnai, Ridolfi, Bianchi, Franchi, \& Tucci, 2019; Pesci, Teza, \& Boschi, 2015). In these cases, thanks to the high spatial resolution of the laser scanning data, it is possible to use point clouds to integrate the data of the traditional survey and obtain information on the geometry of the rock mass remotely.

In the specific case, a calculation algorithm was applied to the point clouds to extract accurate geometric information, useful for the reconstruction and characterization of the rock mass. In particular, through the use of a tool developed in the Matlab environment called DiAna (Gigli \& Casagli, 2011), the discontinuity plans were identified semi-automatically and their spatial orientations were calculated.

The analysis was carried out in correspondence with the main outcrop areas of the limestone rock mass and allowed to extract 2761 discontinuous surfaces. It is however possible that a surface of discontinuity that is not perfectly planar and with high persistence is fragmented into a certain number of "sub-surfaces", with the result that the number of discontinuities extracted is overestimated.

\section{Results}

Thanks to the performed survey campaigns a huge amount of the 3D data of the underground spaces have been obtained and a series of elaborations have been processed capitalizing on the high-resolution point clouds acquired by laser scanning. The elaborations were specifically aimed at:

a) Providing detailed geometric reconstruction of the natural and anthropic outcropping materials in the underground rooms;

b) Extracting a digital model of the detailed soil of the outcrop portions of the limestone rock-mass; c) Integrating the traditional geo-mechanical survey by identifying the main discontinuities affecting the rock mass and dividing them into families;

d) Providing detailed geometric reconstruction of the collapse events that occurred;

e) Identifying main failure mechanisms (Barton, \& Choubey, 1977; Barton, Lien, \& Lunde, 1974; Bieniawski, 1989) of the rock mass in correspondence of the tunnels and underground spaces (Kinematic Analysis).

\section{Discussions}

By applying point clouds segmentation, remotely extracted orientations of planes have been measured. Orientations of joint families modal plans have been identified (BG: $13^{\circ} / 245^{\circ}$, JN1: $76^{\circ} / 069^{\circ}$, JN2: $76^{\circ} / 001^{\circ}$, JN3: $75^{\circ} / 125^{\circ}$ ) and a stereographic projection has been populated.

From the comparison between the stereographic projections, a good correspondence between the joint families measured by scan line survey and the ones extracted applying the semi-automatic method is noticeable. Considering joint families' setting and rockmass characteristic, in terms of material and joints orientation, restoration interventions will be designed and to avoid further collapse events.

The reduction of operators' time exposure to risk-prone areas and the capability to acquire valuable data from inaccessible spaces completes the benefits list.

To survey the whole area, a group of 3 operators spent more than three days. Considering the relatively small extension, the long time spent appears to have resulted from the highly complex surface's morphology and the cramped spaces. Although static TLS is an appropriate technique for this kind of environment, a mobile and presumably remoted operating system, e.g. a TLS mounted on a robotised platform, would have performed the same in less time.

\section{Conclusions}

Point clouds obtained from the high-resolution laser scanning survey, which has been specifically carried out in the underground area, former infirmary, have been exploited to create a detailed 3D model of the area and to integrate traditional geo-mechanical survey with information automatically extracted from the point clouds. The results of the geo-mechanical analysis of the rock mass thus obtained were used to perform a 3D kinematic analysis aimed at assessing the propensity to failure for the various plausible breaking mechanisms in the tunnel sectors analysed.

Finally, a detailed 3D kinematic analysis was carried out on the hypogeum portions where the rock mass emerged, using the discontinuities detected and the mesh obtained from the clouds of laser scanner points as input data. This analysis made it possible to identify which sectors of the infirmary have an adverse orientation in relation to the main kinematic mechanisms of instability (planar sliding, wedge sliding, overturning, free fall), according to the orientation of the discontinuity planes that pervade the rock mass. 
The discontinuity families identified are characterized by decimetric spacing values and mostly have a high degree of alteration and low roughness; these divide the rock mass into small (decimetric) blocks.

Consequently, the general geo-mechanical behaviour of the cluster based on the main classification systems was found to be a material with poor characteristics.

The phenomena of instability observed concern the portions in which the rock mass is directly outcropping and consist more frequently in the detachment of single blocks of decimetric size and secondly, in the detachment of portions of rock mass with a maximum volume of a few m3. In accordance with what emerged from the kinematic analysis, the most observed failure mechanisms are the sliding of wedges and secondly the planar sliding and the free fall.

In particular, it is observed that these phenomena are mainly located in correspondence with some bands of weakness that cross the rock mass parallel to two of the main discontinuity families, or in the intersection areas between tunnels.

\section{Acknowledgements}

The authors want to thank: 1] Italian Ministry of Defence and the Presidency of the Ministry Council for having founded this study, 2] Dr. Geol. Pietro Accolti of Politecnica and Architettura, main promoting company of the temporary grouping of professionals (consortium) for designing, together with: 3] ACPV studio, 4 ]Parallelo and Bit Movies, 5] Architect Gianfranco Tedeschi as Project Manager, 6] Engineer Fabio Camorani as Structural and Geotecnical design, and 7] engineer Francesco Frassineti, 8] Massimo Cavazzuti and 9] Claudio Pongolini for the technical project harmonization. 10] GEOAPP s.r.I. for technical support and outstanding technical experience in managing such a sensitive and complex survey project.

\section{References}

Barton, N. R., \& Choubey, V. (1977). The shear strength of rock joints in theory and practice. Rock Mech., $10,1-54$.

Barton, N. R., Lien, R., \& Lunde, J., (1974). Engineering classification of rock masses for the design of tunnel support. Rock Mech., 6(4), pp. 189-239.

Bieniawski, Z.T. (1989). Engineering Rock Mass classification. Wiley, New York. 251 pages.

Bitelli, G., Balletti, C., Brumana, R., Barazzetti, L., D'Urso, M.G., Rinaudo, F., \& Tucci, G., (2017). Metric documentation of cultural heritage: Research directions from the Italian gamher project (2017) International Archives of the Photogrammetry, Remote Sensing and Spatial Information Sciences, 42 (2W5), pp. 83-90. https://doi.org/10.5194/isprs-archivesXLII-2-W5-83-2017

Bonora, V., Chieli, A., Spanò, A., Testa, P., \& Tucci, G. (2003). 3D Metric-modelling for knowledge and documentation of architectural structures (royal palace in Turin). International Archives of the Photogrammetry, Remote Sensing and Spatial Information Sciences, 34 (5W12), 60-65.

Castagnetti, C., Bertacchini, E,. Capra, A., \& Dubbini, A. (2012). Terrestrial laser scanning for preserving cultural heritage: analysis of geometric anomalies for ancient structures. In: FIG Working Week 2012 - Knowing to Manage the Territory, Protect the Environment, Evaluate the Cultural Heritage, Rome, Italy.

Chías, P., Abad, T., Echeverría, E., De Miguel, M., \& Llorente, P. (2017). Underground surveying: $16^{\text {th }}$ century cellar vaults in the Gallería de Convalecienties, monastery of san Lorenzo del Ecorial. In: International Archives of the Photogrammetry, Remote Sensing and Spatial Information Sciences, XLII2/W3, $179-186$. https://doi.org/10.5194/isprs-archives-XLII-2-W3-283-2017

Gallay, M., Kaňuk, J., Hochmuth, Z., Meneely, J. D., Hofierka, J. \& Sedlák, V., (2015). Large-scale and high-resolution 3D cave mapping by terrestrial laser scanning: a case study of the Domica Cave, Slovakia. International Journal of Speleology, 44(3), 277-291.

Gigli, G., \& Casagli, N., (2011). Semi-automatic extraction of rock mass structural data from high resolution LIDAR point clouds. International Journal of Rock Mechanics \& Mining Sciences, 48(2011): 187-198.

Gigli, G., Mugnai, F., Leoni, L., \& Casagli, N., (2009). Brief communication "Analysis of deformations in historic urban areas using terrestrial laser scanning". Nat. Hazards Earth Syst. Sci., 9, 1759-1761. https://doi.org/10.5194/nhess-9-17592009, 2009

Gracchi, T., Lotti, A., \& Saccorotti, G., (2017). A method for locating rockfall impacts using signals recorded by a microseismic network. Geoenviron Disasters 4, 26. https://doi.org/10.1186/s40677-017-0091-z

Grussenmeyer, P., Alby, E., Landes, T., Koehl, M., Guillemin, S., Hullo, J. F., Assali, P., \& Smigiel, E., (2012). Recording approach of heritage sites based on merging point clouds from high resolution photogrammetry and terrestrial laser scanning, Int. Arch. Photogramm. Remote Sens. Spatial Inf. Sci., XXXIXB5, 553-558. https://doi.org/10.5194/isprsarchives-XXXIX-B5-553- 2012

Hoek, E.; Bray, J.W., (1981) Rock Slope Engineering. Revised 3rd Edition, The Institution of Mining and Metallurgy, London, 341-351.

Malone, H., (2017). Fascist Italy's Ossuaries of the First World War: Objects or Symbols? RIHA Journal 0166,27 June 2017. http://www.riha- journal.org/articles/2017/0150-0176-special-issue-war-graves/0166-malone 
Lo Brutto, M., Sciortino, R., \& Garraffa, A., (2017). RPAS and TLS techniques for archaeological survey: the case study of the archaeological site of Eraclea Minoa (ITALY). International Archives of the Photogrammetry, Remote Sensing and Spatial Information Sciences, Vol. XLII-2/W3, 433-438. https://doi.org/10.5194/isprs-archives-XLII-2-W3-4332017

Mucchi, L., Jayousi, S., Martinelli, A., Caputo, S., Intrieri, E., Gigli, G., Gracchi, T., Mugnai, F., Favalli, M., Fornaciai, A., \& Nannipieri, L. A., (2018). Flexible Wireless Sensor Network Based on Ultra-Wide Band Technology for Ground Instability Monitoring. Sensors, 18, 2948.

Mugnai, F., Lombardi, L., Tucci, G., Nocentini, M., Gigli, G., \& Fanti, R. (2019). Geomatics in bridge structural health monitoring, integrating terrestrial laser scanning techniques and geotechnical inspections on a high value cultural heritage. Int. Arch. Photogramm. Remote Sens. Spatial Inf. Sci., XLII-2/W11, 895-900. https://doi.org/10.5194/isprsarchives-XLII-2-W11-895-2019

Mugnai, F., Ridolfi, A., Bianchi, M., Franchi, M., \& Tucci, G., (2019). Developing affordable bathymetric analysis techniques using non-conventional payload for cultural heritage inspections. Int. Arch. Photogramm. Remote Sens. Spatial Inf. Sci., XLII-2/W15, 807-811. https://doi.org/10.5194/isprs-archives-XLII-2-W15-807-2019

Olsen, M., Kuester, M., Chang, B., \& Hutchinson, T., (2010). Terrestrial laser scanning-base structural damage assessment. Comput Civil Eng, 24(3), 264-272. https://doi.org/10.1061/(ASCE)CP.1943-5487.0000028

Pesci, A., Teza, G., \& Boschi, E. (2015). Laser scanning-based detection of morphological changes of a historical building occurred during a seismic sequence: Method and Case study. International Journal of Geomatics and Geosciences, 5(3) 427-447.

Priest, S. D., \& Hudson, J.A., (1976). Discontinuity spacings in rocks. Int. Journ. Rock Mech. Min. Sci. \& Geomech. Abstracts, 13, 135-148.

Priest, S. D., (1993). Discontinuity analysis for rock engineering. London: Chapman \& Hall.

RIEGL Laser Measurement Systems GmbH, (2004). RIEGL - RIEGL Laser Measurement Systems. Technical data Retrieved March 15, 2021, from www.riegl.com.

Remondino, F., Rizzi, A., Jimenez, B., Agugiaro, G., Baratti, G., \& Amicis, R., (2011). The Etruscans in 3D: From Space to Underground. Geoinformatics FCE CTU, 6, pp. 283-290. https://doi.org/10.14311/gi.6.35.

Remondino, F., (2011). Heritage recording and 3D modeling with photogrammetry and 3D scanning. Remote Sensing, 3, pp. 1104-1138.

Roncella, R., Forlani, G., \& Remondino, F. (2005). Photogrammetry for geological applications: automatic retrieval of discontinuity orientation in rock slopes. In: Videometrics IX, electronic imaging, IS\&T/SPIE, Proceedings of the 17th annual symposium (pp. 17-27).

Thiel, K.H., \& Wehr, A., (2004). Performance Capabilities of Laser-Scanners - An Overview and Measurement Principle Analysis. International Archives of Photogrammetry, Remote Sensing and Spatial Information Sciences 36 (Part 8/W2), 14-18.

Varady,T., Facello, M.A., \& Terek, Z., (2007). Automatic extraction of surface structures in digital shape reconstruction. Comput Aided Des, 39(5), 379-388. https://doi.org/10.1016/j.cad.2007.02.011

Tucci, G., Bonora, V., Fiorini, L., \& Conti, A., (2016). The Florence baptistery: 3-D Survey as a knowledge tool for historical and structural investigations. International Archives of the Photogrammetry, Remote Sensing and Spatial Information Sciences, 41, 977-984. https://doi.org/10.5194/isprsarchives-XLI-B5-977-2016

Wagner, W., Ullrich, A., Ducic, V., Melzer, T., \& Studnicka, N., (2006). Gaussian Decomposition and Calibration of a Novel Small- Footprint Full-Waveform Digitising Airborne Laser Scanner. ISPRS Journal of Photogrammetry \& Remote Sensing, 60(2): 100-112. 